\title{
Muffins Obtained with Some Vegetal Powders as Fat Replacers
}

\author{
Roxana E. TUFEANU*, Mihaela A. TIȚA, Ovidiu TIȚA \\ Department of Agriculture Science, Food Process Engineering, Lucian Blaga University of Sibiu, Romania \\ ${ }^{*}$ Corresponding author, e-mail: elena.tufeanu@ulbsibiu.ro
}

Bulletin UASVM Animal Science and Biotechnologies 75(1)/ 2018

Print ISSN 1843-5262; Electronic ISSN 1843-536X

DOI:10.15835/buasvmcn-asb: 000317

\begin{abstract}
Chia seeds and watermelon rind powder were used to produce low-fat muffins in which butter has been replaced at different levels.The utilization of the fat replacers has increased the moisture content and water activity of the samples. The initial moisture content was ranging from $24.41 \%$ in control sample to $31.89 \%$ in muffins with $100 \%$ butter replacement by using the watermelon rind paste. The water activity presented values between $0.863-$ 0.899 during storage at ambient temperature for 10 days. Minerals analysis indicated that through the addition of the powders, an increase in the mineral content of the samples can be achieved. $P$ was the most abundant mineral followed by K. The samples obtained by replacing the butter with vegetal powders can provide between $49.29 \%$ - 58.51\% phosphorus; $18.91 \%-21.45 \%$ selenium and $15.04 \%-18.48 \%$ manganese from the recommended daily intake. These vegetal powders can be used as ingredients for partial or total replacement of fat in muffins due to their ability to improve the nutritional quality and to maintain the physical-chemical and sensory characteristics at level of acceptability.
\end{abstract}

Keywords: chia seeds powder, watermelon rind powder, low fat muffins

\section{INTRODUCTION}

Nowadays, consumers are much more informed about the food products they consume than past generations. This increase in knowledge increases proportionally the demand for more nutritious, qualitative and tasty foods. Consumers are more aware of food problems and monitor and adjust what they consume because they have become more concerned about improving their overall health through daily intake. It is also observed an increase in awareness of the adverse effects caused by high fat consumption and consequently, people have approached a diet based on low fat content (Akin, and Kirmaci, 2015).

Lately, consumers are turning their attention increasingly more on functional foods. These products, due to the bioactive functional compounds provide benefits on human health, besides the basic nutritional role (Coelho, and Salas-Mellado, 2014) Also, functional foodstuffs may have significant roles in reducing the risk of chronic diseases (Al-Sheraji et al., 2013).

Chia (Salvia hispanica L.) has been cultivated in Mexico since ancient times. Chia seeds were used by the Aztec tribes for food and for medicinal purposes (Saphier et al., 2017). These seeds present a significant amount of lipids, from which approximately $60 \%$ are omega- 3 fatty acids and 17 $26 \%$ omega- 6 fatty acids. Also, chia seeds contain dietary fiber and proteins with high biological value (Ixtaina et al., 2011). According to Capitani et al. (2012) these seeds present a high antioxidant activity associated with its polyphenolic content and with the presence of tocopherols.

Watermelon belongs to the Cucurbitaceae family, species Citrulluslanatus and is recognized in the summer period as an excellent refreshing fruitdue to its high water content (El-Badry et al., 2014; Egbuonu, 2015). In Romania, the watermelon crop is considered important. Usually, watermelon pulpis the most consumed part of the fruit, while 
the rind and the seeds are considered wastes. It is known that food wastes can have a negative environmental and public health impact. On the other hand, by-products which mainly consist of peels and seeds are considered important sources of valuable compounds (Morais et al., 2015). According to Rimando and Perkins-Veazie (2005) watermelon rinds contain important amounts of citrulline, an amino acid with antioxidant capacity and roles in vasodilatation. Also, watermelon is an important source of vitamins, mineral salts and antioxidants compounds (phenolics and carotenoids) (Perkins- Veazie et al., 2002 and 2007).

The aim of this study was to obtain muffins with low fat content and enriched nutritional value by replacing butter with powders obtained from chia seeds and watermelon rind.

\section{MATERIALS AND METHODS}

The muffins ingredients were wheat flour, corn starch, skimmed milk, butter (65\% fat), eggs, sugar, baking soda, salt, emulsifier, chia seeds and watermelon rind powder. All the ingredients were procured from local markets. Watermelon fruit was washed to remove impurities after which it was sliced and the rind was collected. The respective rind was milled with a knife mill GRINDOMIX GM 200 , Retsch and then dehydrated at $50^{\circ} \mathrm{C}$ in the oven, POL-EKO model, until the sample reached a constant mass. Then the dehydrated sample was again milled to obtain the powder, which was kept in airtight container, at room temperature, prior to use. Also, the chia seeds were milled to obtain the powder.

Muffins were prepared by replacing butter with chia gel and watermelon rind paste in different concentrations and compared with control muffins. Chia powder and watermelon rind powder were hydrated with milk, in a ratio of $1: 10$, respectively $1: 4$ (for 30 minutes- 1 hour) to obtain the fat replacers. Muffins were baked for 25 minutes at $180^{\circ} \mathrm{C}$ in an electric oven preheated to this temperature. After cooling for $10 \mathrm{~min}$, muffins were removed from the moulds and were left at room temperature for $1 \mathrm{~h}$. The muffins were stored at $20^{\circ} \mathrm{C} \pm 3^{\circ} \mathrm{C}$ for 10 days in alimentary bags.

Moisture content of samples was determined by air-oven method according to SR 91:2007.

The water activity of products was determined using Novasina Labmaster aw.
Minerals content ( $\mathrm{Ca}, \mathrm{Cu}, \mathrm{Fe}, \mathrm{K}, \mathrm{Mg}, \mathrm{Mn}, \mathrm{P}, \mathrm{Zn}$ ) was determined by Inductively Coupled Plasma Optical Emissions Spectrometry and for Se was used Atomic Absorption Spectrometry, technique FIAS-Furnace. Microwave Reaction System SOLVMultiwave Pro with Rotor HF 16-100 (Anton Paar) was used for the sample mineralization. Approximately $1 \mathrm{~g}$ of sample was weighed in the reaction vessels of the mineralization system and $2 \mathrm{~mL} \mathrm{H}_{2} \mathrm{O}_{2}$ (30\%), $11 \mathrm{~mL} \mathrm{HNO}_{3}(65 \%)$ and $1 \mathrm{~mL} \mathrm{HCl}$ (37\%) were added. Concentrations of the minerals were analysed by using ICP-OES (Optima 8300 DV, Perkin Elmer) and AAS (PinAAcle900T, Perkin Elmer) at different wavelengths using argon as carrier gas: Ca-317.93; $\mathrm{Cu}-327.39$; $\mathrm{Fe}-238.20$; K-766.49; Mg-285.21; Mn-257.61; P-214.91; Zn213.85; Se-196.03 nm.

Muffins were evaluated for sensory properties by 15 untrained panelists. They evaluated each sample for appearance, appearance in section, colour, porosity, taste and sweetness on 7-point scale, where $1=$ dislike extremely and $7=$ like extremely. The panellists received the muffin samples, coded, on a tray, a bottle of $500 \mathrm{~mL}$ with water and the evaluation sheet. Five samples for each formulation were tested in a random order at room temperature.

The extraction method used in this study is adapted from the methods used to determine the total polyphenol content of Psyllium (leaves, seeds and bran (Patel et al., 2016) and of muffins with apple skin powder (Rupasinghe et al., 2009). The dried sample (500 mg) was extracted with 10 $\mathrm{mL}$ of methanol:water:hydrochloric acid $0.12 \mathrm{M}$ $=70: 29: 1(\mathrm{v} / \mathrm{v} / \mathrm{v})$ at room temperature for 24 hours. Then, the mixture was maintained on the ultrasonic water bath for 30 minutes at $25^{\circ} \mathrm{C}$. The supernatant was collected and centrifuged at $8000 \mathrm{rpm}$ for 10 minutes and was brought to dryness with Hei-VAP Precision Rotary Evaporator (Heidolph) under reduced pressure, at $40^{\circ} \mathrm{C}$. The residue was taken up in $10 \mathrm{~mL}$ of methanol, filtered, and then filled to $10 \mathrm{~mL}$ with the same solvent.

The total polyphenolic content of the extracts obtained was determined by an adapted method from European Pharmacopoeia (2014), using Folin-Ciocalteu reagent. To $0.4 \mathrm{ml}$ extract were added $1 \mathrm{~mL}$ Folin-Ciocalteu reagent, $15 \mathrm{~mL}$ purified water and $2 \mathrm{~mL} \mathrm{Na}_{2} \mathrm{CO}_{3} 290 \mathrm{~g} / \mathrm{L}$. The mixture is maintained for 10 minutes on the ultrasonic water 
Table 1. Recipe for control muffins (C), muffins with chia gel (CM) and muffins with watermelon rind paste (WM)

\begin{tabular}{cccccc}
\hline \multirow{2}{*}{ Ingredients (g) } & \multicolumn{5}{c}{ Samples } \\
\cline { 2 - 6 } & $\mathrm{C}$ & $\mathrm{CM} 1$ & $\mathrm{CM} 2$ & WM1 & WM2 \\
\hline Flour & 90 & 90 & 90 & 90 & 90 \\
\hline Corn Starch & 10 & 10 & 10 & 10 & 10 \\
\hline Eggs & 60 & 60 & 60 & 60 & 60 \\
\hline Sugar & 50 & 50 & 50 & 50 & 50 \\
\hline Butter & 45 & 22.5 & 0 & 22.5 & 0 \\
\hline Milk & 42 & 42 & 42 & 42 & 42 \\
\hline Baking Soda & 3 & 3 & 3 & 3 & 3 \\
\hline Salt & 1 & 1 & 1 & 1 & 1 \\
\hline Emulsifier (Emulbel ED) & 0.18 & 0.18 & 0.18 & 0.18 & 0.18 \\
\hline Chia seeds gel & 0 & 22.5 & 45 & 0 & 0 \\
\hline Watermelon rind paste & 0 & 0 & 0 & 22.5 & 45 \\
\hline
\end{tabular}

bath and then incubated at $40^{\circ} \mathrm{C}$ for 20 minutes. The absorbance at $760 \mathrm{~nm}$ with CECIL $1021 \mathrm{UV}$ VIS spectrophotometer was measured. Gallic acid was used as standard for the calibration curve. The total phenolic content (TPC) was expressed as milligram equivalent of gallic acid per 100 grams of dried sample (mg GAE/100 g d. s.). All analyses were performed in triplicate and the mean values are reported.

\section{RESULTS AND DISCUSSIONS}

The moisture content of the muffin samples was determined over a 10-day storage period and the results are shown in Table 1. It can be observed that the utilization of fat replacers has increased the moisture content of the samples. The highest humidity values were recorded for samples in which the butter was completely replaced. The production of muffins with high moisture can be attributed to the large quantities of water derived from the incorporated vegetal pastes and gels and to the high water affinity of the replacers used.

Similar values of humidity have been reported by Jauharah et al., (2014) for muffins obtained by replacing wheat flour with corn baby powder. The sample obtained with wheat flour had an initial moisture content of $25.23 \%$, but by replacing it with baby corn powder, the moisture increased, so for muffins with $30 \%$ flour replacement, a moisture content of $30.44 \%$ was obtained.

Similar results on the increase in moisture content were also reported for cookies obtained by replacing butter with avocado puree and Oatrim (Wekwete, and Navder, 2007) and for the cakes made by replacing vegetable fat with Yuja pectin gel, which recorded humidity values ranging from 34-35\% depending on the percentage of substitute used (Lim et al., 2014).

From Table 2, it can be observed that the water activity values for all formulations with fat substitutes were higher compared to the control.

The muffin samples presented values of water activity between $0.863-0.899$. These values greater than 0.7 - the limit for the moulds development (Andrade et al., 2016), indicate for all samples a critical stability during storage for 10 days.

In order to avoid the development of microorganisms, the quality of the raw materials and the hygienic conditions during processing and in particular after obtaining the product must be taken into account.

Wekwete and Navder (2007) also noticed that the water activity was higher for cookies prepared with avocado puree as compared to the control sample.

For all the samples can be observed an increase of the water activity with the increase of the storage period. Similar results were reported by Bhise and Kaur (2015) for muffins made with fiber from oats, barley and psyllium. They presented water activity values between 0.81 0.92 for the control sample during storage at ambient temperature for 35 days. Values of water activity ranging from $0.87-0.90$ were presented 
Table 2. Physical-chemical characteristics of muffins

\begin{tabular}{ccccccc}
\hline & $\begin{array}{c}\text { Period } \\
\text { (days) }\end{array}$ & C & CM1 & CM2 & WM1 & WM2 \\
\hline \multirow{4}{*}{$\begin{array}{c}\text { moisture } \\
\text { (\%) }\end{array}$} & 1 & 24.41 & 27.23 & 32.44 & 26.71 & 31.89 \\
\cline { 2 - 7 } & 3 & 24.11 & 26.52 & 31.72 & 26.64 & 31.52 \\
\cline { 2 - 7 } & 5 & 23.74 & 25.56 & 30.96 & 26.36 & 30.76 \\
\cline { 2 - 7 } & 7 & 23.26 & 25.22 & 29.91 & 26.06 & 29.83 \\
\hline \multirow{4}{*}{ aw } & 10 & 22.91 & 24.82 & 29.07 & 25.63 & 29.14 \\
\cline { 2 - 7 } & 1 & 0.863 & 0.874 & 0.891 & 0.864 & 0.879 \\
\cline { 2 - 7 } & 3 & 0.863 & 0.875 & 0.891 & 0.864 & 0.881 \\
\hline & 7 & 0.864 & 0.876 & 0.891 & 0.869 & 0.881 \\
\hline & 10 & 0.870 & 0.876 & 0.896 & 0.870 & 0.882 \\
\hline
\end{tabular}

Table 3. The mineral content of the muffins samples

\begin{tabular}{|c|c|c|c|c|c|}
\hline \multirow{2}{*}{$\begin{array}{c}\text { Minerals } \\
\text { (mg/100 g) }\end{array}$} & \multicolumn{5}{|c|}{ Samples } \\
\hline & $\mathrm{C}$ & CM1 & CM2 & WM1 & WM2 \\
\hline $\mathrm{Ca}$ & 65.57 & 88.17 & 113.60 & 81.98 & 100.00 \\
\hline $\mathrm{Cu}$ & 0.15 & 0.12 & 0.13 & 0.10 & 0.09 \\
\hline $\mathrm{Fe}$ & 1.19 & 1.22 & 1.36 & 1.16 & 1.20 \\
\hline $\mathbf{K}$ & 151.20 & 165.20 & 196.60 & 196.70 & 262.30 \\
\hline $\mathrm{Mg}$ & 17.88 & 23.91 & 29.48 & 23.32 & 26.61 \\
\hline Mn & 0.29 & 0.33 & 0.37 & 0.30 & 0.31 \\
\hline $\mathbf{Z n}$ & 0.78 & 0.90 & 0.97 & 0.88 & 0.89 \\
\hline $\mathbf{P}$ & 340.30 & 377.90 & 409.60 & 345.00 & 367.30 \\
\hline Se & 0.01 & 0.01 & 0.01 & 0.01 & 0.01 \\
\hline
\end{tabular}

by Andrade et al., (2016) for muffins in which vegetable fat was reduced.

The results obtained by determining the mineral content by ICP-OES and AAS, FIAS furnace techniques are shown in Table 2.

For muffins with chia seeds gel a significant increase in $\mathrm{P}, \mathrm{Ca}, \mathrm{Zn}, \mathrm{K}$ and $\mathrm{Mg}$ content as compared with the control was observed. The most abundant mineral salt presented in muffins was $\mathrm{P}$, followed by K.

By using the watermelon rind powder, an increase in the mineral content of the samples can also be achieved. Appreciable amount of P, K and Ca were found in the muffins obtained with watermelon rind paste as fat replacer.

This by-product can contributes to the nutritional value improvement of the muffins. The samples obtained by replacing $100 \%$ butter with watermelon rind paste were remarked for the highest $\mathrm{K}$ content.

Taking into account the daily reference intakes of minerals for adults according to the Regulation (EU) No 1169/2011, was calculated the contribution of these powders to achieve the recommended daily intake in these nutrients. The values obtained are presented in Figure 1.

The samples obtained with chia gel can provide $53.99 \%$ (CM1), 58.51\% (CM2) phosphorus; $18.91 \%$ (CM1), 21,27\% (CM2) selenium, 11.66\% (CM1), 12.52\% (CM2) copper and 16.34\% (CM1), $18.48 \%$ (CM2) manganese from recommended daily intake.

The muffins with watermelon rind paste addition can provide $49.29 \% \mathrm{P}$ (samples with partial replacement of butter) and $52.47 \% \mathrm{P}$ (total replacement of butter) from recommended daily 


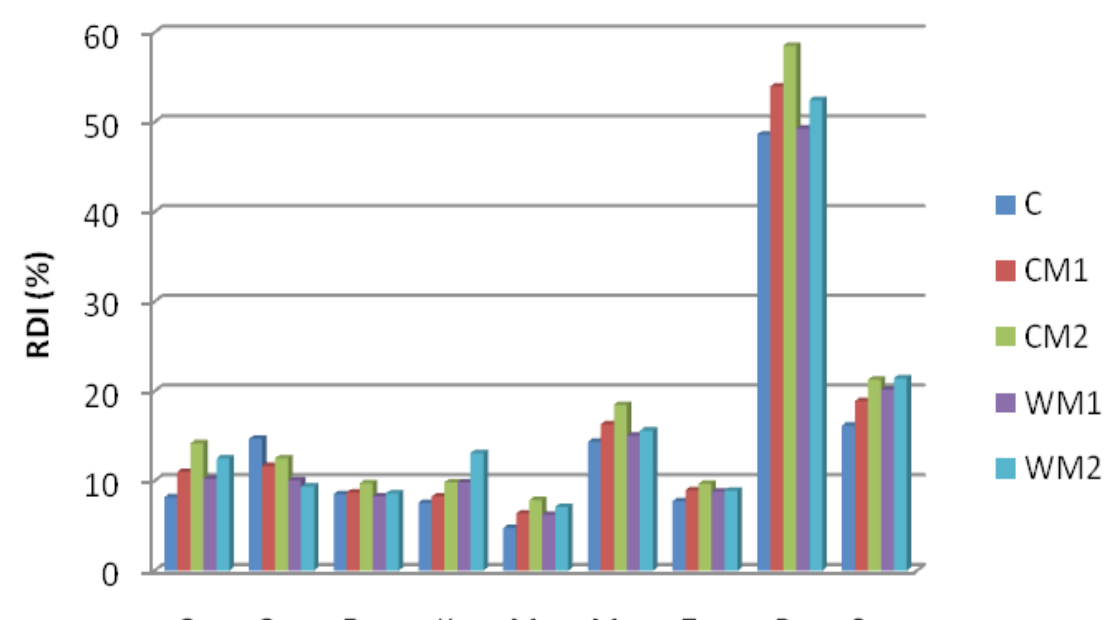

$\mathrm{Ca} \mathrm{Cu} \quad \mathrm{Fe} \quad \mathrm{K} \quad \mathrm{Mg} \quad \mathrm{Mn} \quad \mathrm{Zn} \quad \mathrm{P} \quad \mathrm{Se}$

Figure 1. Percent of minerals from recommended daily intake (\% RDI)

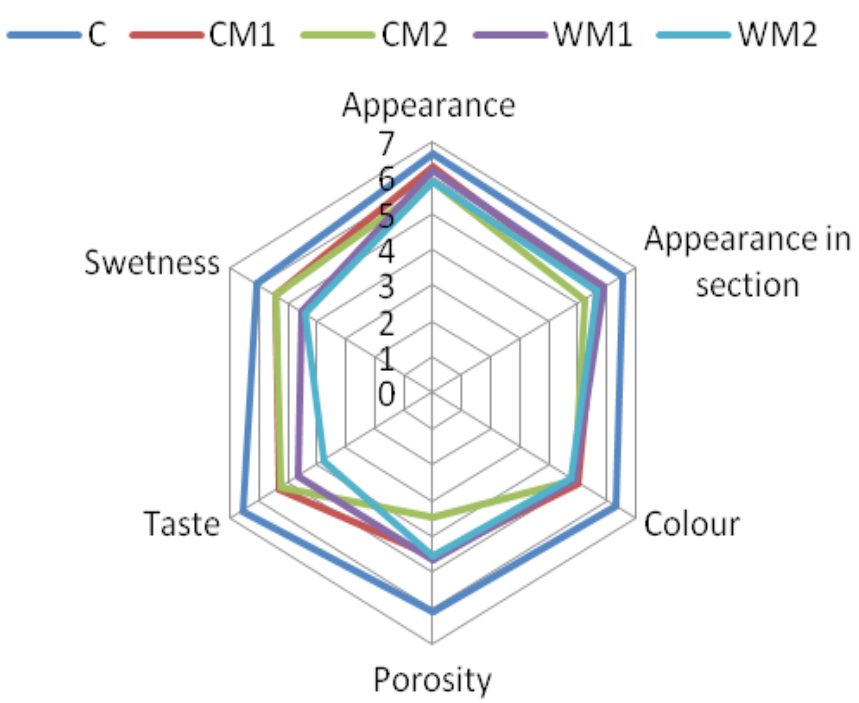

Figure 2. Mean values for the sensory properties of muffins

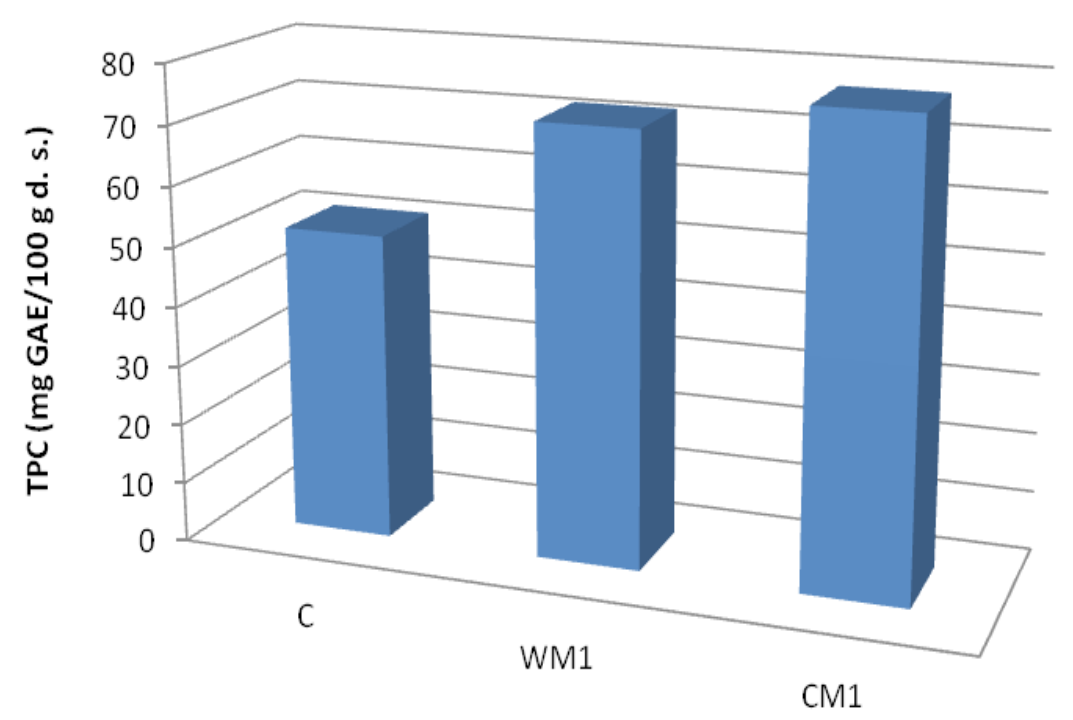

Figure 3. Total polyphenolic content in muffins 
intake. With regard to selenium, these samples can contribute with about 20\%. Also, 15.04\% and $15.62 \%$ magnesium intake can be provided. The amount of potassium that can be assured by muffins with $50 \%$ butter reduction is about $10 \%$, and for those produced without butter, the intake is $13.12 \%$.

In Figure 2 are presented the results of the sensory analysis.

All attributes varied by adding fat substitutes. Although the samples were prepared with the same amount of sugar, the results show that the vegetal powders addition has affected the sweetness perception. The lowest sweetness values were obtained for muffins with watermelon rind paste. This may suggest that watermelon powder used as a fat substitute can come with a specific, pronounced taste that can interfere with the correct perception of sweet taste. Some evaluators have indicated that the taste of muffins with watermelon rind paste is slightly astringent.

The appearance of the muffins was one of the attributes that did not vary significantly with the addition of fat substitutes.

The porosity of the analysed products was affected by the reduction of the butter content. This characteristic is mainly influenced by the quality and quantity of gluten from flour and its ability to form and retain the gases and at the same time by the presence of fats to disrupt the gluten network, in order to produce final products with a uniform structure and high volume.

The colour was another sensory characteristic influenced by the use of vegetable powders as fat substitutes. In the case of samples obtained with watermelon rind powder, the lowest values for colour were recorded.

Based on sensory analysis it can be stated that the reduction of fat by $50 \%$ provides acceptable results regarding the sensory properties compared to the total replacement of fat.

The results of the total polyphenol content determination in muffins are shown in Figure 3. The selected samples for the determination were those obtained by reducing the amount of butter by $50 \%$, because according to the results of the sensory analysis it was found that these products were better accepted by the evaluators.

From the graphical representation can be observed that the utilization of fat substitutes based on vegetal products has resulted in an increase of the total content of polyphenols. Muffins with chia gel have presented the highest content of polyphenols - $77.43 \mathrm{mg}$ GAE/ $100 \mathrm{~g}$ d. s., followed by muffins with watermelon rind paste - $72.07 \mathrm{mg} \mathrm{GAE} \mathrm{/} 100 \mathrm{~g}$ d.s. These results are due to the important polyphenolic content of the powders used. In one of our previous studies, the total content of polyphenols of these powders was determined, and the chia seeds powder showed a higher value compared with the watermelon rind powder.

In the preservation of polyphenols from muffins the temperature plays an important role. In a study of Górnaś et al., (2016) was observed that the baking in a conventional oven at temperature $220^{\circ} \mathrm{C}$ for 14 minutes had the best effect on polyphenols preservation. To deeply understand the effect of high temperature on polyphenols is necessary to determine their composition. For example, Górnaś et al., (2016) observed that the most unstable compounds in the muffins enriched by strawberry, sour cherry, raspberry or black currant pomace were anthocyanins. In contrast the flavonol glycosides were the most stable. In the very next future our intent is to investigate the polyphenols stability in muffins at baking temperature, especially due to the varied composition of these compounds in the vegetal powders.

\section{CONCLUSION}

The utilization of fat replacers has increased the moisture content of the samples. The highest humidity values were recorded for samples in which the butter was completely replaced. For all the samples was observed an increase of the water activity with the increase of the storage period.

Minerals content analysis indicated that through the addition of powders from watermelon rind and chia seeds, an increase in the mineral content of the samples can be achieved. Also, the utilization of fat substitutes based on vegetal powdersincreased the total polyphenols content of muffins.

The sensory analysis indicated that the reduction of butter by $50 \%$ can provide better acceptable results compared to the total replacement of fat.

These vegetal powders can be used as ingredients for replacement of fat in muffins or others baked products due to their ability to improve the 
nutritional quality and to maintain the physicalchemical and sensory characteristics at level of acceptability.

Acknowledgements. Authors thank to SCIENT-

Research Center for Instrumental Analysis, Bucharest, Romania for the facilities provided for the minerals analysis.

\section{REFERENCES}

1. Akin MS, Kirmaci Z (2015). Influence of fat replacers on the chemical, textural and sensory properties of lowfat Beyaz pickled cheese produced from ewe's milk. International Journal of Dairy Technology, 68: 127-135.

2. Al-Sheraji SH, Ismail A, Manap MY, Mustafa S, Yusof RM, Hassan FA (2013). Prebiotics as functional foods: A review. Journal of Functional Foods, 5: 1542-1553.

3. Andrade FJET, Farias MDP, Vieira SKV, Sá DMAT, Egito AS, Carneiro-da-Cunha MG (2016). Fat content evaluation in physical properties and texture profile of cakes, X CIGR Section IV International Technical Symposium, Food: the tree that sustains life, Gramado/RS, Brazil.

4. Bhise S, Kaur A (2015). Fortifying muffins with psyllium husk fibre, oat fiber and barley fibre to improve quality and shelf life. Carpathian Journal of Food Science and Technology, 7: 5-16.

5. Capitani MI, Spotorno V, Nolasco SM, Tomás MC (2012). Physicochemical and functional characterization of by-products from chia (Salvia hispanica L.) seeds of Argentina. Food Science and Technology, 45:94-102.

6. Coelho MS, Salas-Mellado MM (2014). Chemical characterization of CHIA (Salvia hispanica L.) for use in food products. Journal of Food and Nutrition Research, 2: 263-269.

7. Egbuonu AC (2015). Comparative assessment of some mineral, amino acid and vitamin compositions of watermelon (Citrullus lanatus) Rind and Seed. Asian Journal of Biochemistry, 10: 230-236.

8. El-Badry N, El-Waseif MA, Badr SA, Ali HE (2014). Effect of addition watermelon rind powder on the rheological, physiochemical and sensory quality attributes of pan bread. Middle East Journal of Applied Sciences, 4: 10511046.

9. European Pharmacopoeia 8. (2014). Strasbourg Cedex: The Directorate for the Quality of Medicines and HealthCare of the Council of Europe (EDQM).

10. Górnaś $\mathrm{P}$, Juhṇeviča-Radenkova $\mathrm{K}$, Radenkovs $\mathrm{V}$, Mišina I, Pugajeva I, Soliven A, Seglina D (2016). The impact of different baking conditions on the stability of the extractable polyphenols in muffins enriched by strawberry, sour cherry, raspberry or black currant pomace. LWT - Food Science and Technology, 65: 946-953.

11. Ixtaina VY, Martínez ML, Spotorno V, Mateo CM, Maestri DM, Diehl BWK (2011). Characterization of chia seed oils obtained by pressing and solvent extraction. Journal of Food Composition and Analysis, 24: 166-174.

12. Jauharah MZA, Rosli WIW, Robert SD (2014). Physicochemical and sensorial evaluation of biscuit and muffin incorporated with young corn powder. Sains Malaysiana, 43: 45-52.

13. Lim J, Ko S, Lee S (2014). Use of yuja (Citrus junos) pectin as a fat replacer in baked foods. Food Science and Biotechnology, 23: 1837-1841.

14. Morais DR, Rotta EM, Sargi SC, Schimidt EM, Bonafé EG, Eberlin MN, Sawaya, ACHF, Visentainer JV (2015). Antioxidant activity, phenolics and UPLC-ESI (-)-MS of extracts from different tropical fruits parts and processed peels. Food Research International, 77: 392-399.

15. Patel M K, Mishra A, Jha B (2016). Non-targeted metabolite profiling and scavenging activity unveil the nutraceutical potential of psyllium (Plantago ovata Forsk). Frontiers in Plant Science, 7:1-17.

16. Perkins-Veazie P, Collins JK, Clevidence B (2007). Watermelons and health. Acta Horticulturae (ISHS) 731:121-128.

17. Perkins-Veazie P, Maness N, Roduner R (2002). Composition of orange, yellow, and red-fleshed watermelons. Cucurbitacea, 436-440.

18. REGULATION (EU) No 1169/2011 OF THE EUROPEAN PARLIAMENT AND OF THE COUNCIL of 25 October 2011 on the provision of food information to consumers.

19. Rimando AM, Perkins-Veazie P (2005). Determination of citrullin in watermelon rind. Journal of Chromatography, 1078: 196-200.

20. Rupasinghe HPV, Wang L, Huber GM, Pitts NL (2008). Effect of baking on dietary fibre and phenolics of muffins incorporated with apple skin powder. Food Chemistry, 107: 1217-1224.

21. Saphier O, Silberstein T, Kamer H, Ben-Abu Y, Tavor D (2017). Chia seeds are richer in polyphenols compared to flax seeds. Integrative Food, Nutrition and Metabolism, 4: 1-4.

22. Wekwete B, Navder KP (2008). Effects of avocado fruit puree and oatrim as fat replacers on the physical, textural and sensory properties of oatmeal cookies. Journal of Food Quality 31:131-141. 